\title{
BIODIGESTORES COMO FERRAMENTA PARA UM ENSINO INTEGRADOR
}

\author{
Zenilda Ribeiro Da Silva ${ }^{1}$ \\ Ligia Marcelino Krelling ${ }^{2}$ \\ Marcos Antonio Florczak ${ }^{3}$
}

\begin{abstract}
Resumo: Este trabalho realizado por meio de uma pesquisa de observação participante, que busca uma instrumentalização para o ensino das Ciências Naturais $(\mathrm{CN})$ envolveu jovens do Ensino Médio regular de uma escola estadual em Araucária-PR. O objetivo foi propor estratégias para ensinar de forma integrada, por meio do conceito unificador energia. Para análise dos dados utilizamos a perspectiva qualitativa de análise de conteúdos como propõe Bardin (1977). Para alcançar esta meta foi proposto a construção de um modelo didático pedagógico de biodigestor que deu suporte ao conteúdo teórico trabalhado de modo dialogado em sala de aula. O trabalho aqui apresentado foi concebido de forma a contemplar os dois eixos fundamentais recomendados pelos PCN para o ensino de $\mathrm{CN}$ : a contextualização e a interdisciplinaridade. A contextualização ocorreu por meio de discussão, em sala de aula, relacionada ao processo de decomposição da matéria orgânica, que ao longo da biodigestão permitiu a visualização da formação do gás metano e outros gases que foram produzidos durante este processo. A interdisciplinaridade, por sua vez, foi explorada no contexto de uma abordagem em que os fenômenos naturais, para serem vislumbrados de forma plena, necessitam da visão integrada de várias disciplinas. Ênfase foi dada às conexões entre os processos de decomposição da matéria orgânica e sua consequente produção de gás, o qual pode ser utilizado, por exemplo, na produção de energia elétrica.
\end{abstract}

Palavras-chave: Ensino de Ciências. Interdisciplinaridade. Energia. Biodigestor.

\section{BIODIGESTORS AS A TOOL TO AN INTEGRATING EDUCATION}

\begin{abstract}
This article was done by participatory research, that aims to articulate with Natural Science (NS) Education and it involved regular middle school students of a state school in Araucária-PR. The goal was to propose strategies to teach in an integrated way, through the unified conceptof energy.For the data it was used the qualitative content analysis approach as proposed by Bardin (1977). To reach this goal it was suggested a construction ofbiodigested pedagogical didactic model that supported the theoretical content, built on conversations in classroom. The work here represented was conceived in order to contemplate the two fundamental axis recommended by the (PCN -National Curricular Parameters), for the education of NS: the contextualization and the interdisciplinarity. The contextualization occurred through conversations in classroom relating to the process of decomposition of organic matter, that along with the biodigestion, allowed the visualization of the methanegas formation as well other gases produced in the process. The interdisciplinarity, hence, was explored in the context of an

\footnotetext{
${ }^{1}$ Doutoranda em Meio Ambiente e desenvolvimento: UFPR. Mestre em Ensino de Ciências: Universidade Tecnológica Federal do Paraná - Curitiba. Professora Educação Básica Secretaria de Educação do Paraná (SEEDPR). E-mail: zenilda_silva22@hotmail.com.

${ }^{2}$ Mestre em Ensino de Ciências: Universidade Tecnológica Federal do Paraná-Curitiba. Professora de Ciências da Prefeitura Municipal de Curitiba. E-mail: ligiak.supremo@gmail.com

${ }^{3}$ Doutor em Astronomia: Possui graduação em Física pela Universidade Federal do Paraná. Mestrado em Física pela Universidade Federal do Paraná e Doutorado em Astronomia pelo Observatório Nacional, com estágio no Observatoire de Meudon-Paris. Professor associado da Universidade Tecnológica Federal do Paraná. Tem experiência na área de Astronomia, com ênfase em Astrofísica do Sistema Solar. Atualmente atua na área de ensino de física e astronomia. E-mail: florczak@utfpr.edu.br.
} 
approach in which the natural phenomena to be broadly observed, required an integrated view of many disciplines. The emphasis was given to the connections amongst the decomposition process of the organic matter and its gas production, which could then be utilized, for example, in the energetic production.

Keywords: Science Education. Interdisciplinarity. Energy. Biodigester.

\section{Introdução}

O presente artigo traz um recorte da dissertação Silva (2015) 'O ensino de Ecologia mediado pelo conceito unificador energia: o biodigestor enquanto modelo didático para uma abordagem interdisciplinar, desse modo, a presente pesquisa tem como objetivo geral desenvolver estratégias de utilização de conceitos comuns nas Ciências da Natureza, em especial o tema energia. Parte-se do pressuposto de que o assunto energia possui característica altamente interdisciplinar e, por isso, pode ser usado como ponte integradora entre conceitos das $\mathrm{CN}$.

Assim, esta metodologia busca contribuir para o desenvolvimento de propostas de ensino interdisciplinares, tendo em vista a formação de sujeitos aptos a compreender as Ciências e sua importância na sociedade. Portanto, trata-se de uma proposta metodológica que busca desenvolver práticas de ensino-aprendizagem pautadas em um pensamento interdisciplinar e no estímulo à autonomia dos estudantes na construção do conhecimento, tendo em vista os avanços e dilemas associados às $\mathrm{CN}$ na sociedade atual.

Busca-se aqui uma estratégia didática de ensino e aprendizagem que ofereça aos estudantes a oportunidade de observar os fenômenos naturais e, a partir desta observação, propor hipóteses, discutir seus pareceres em grupo, buscar resultados, formular relações entre a teoria e a prática. Assim, esta pesquisa procura estabelecer estratégias para utilização, em aulas de Ciências da Natureza, de conceitos comuns e que apresentam característica altamente interdisciplinar como, por exemplo, o tema energia. Busca-se, assim, aprofundar e ampliar discussões, a partir de uma perspectiva interdisciplinar, com foco em atividades em sala de aula.

Neste recorte, a finalidade é mostrar alguns resultados alcançados com a desenvolvimento e observação do biodigestor, no conteúdo Ecologia. Os relatórios foram utilizados como forma de avaliação da aprendizagem dos estudantes.

$\mathrm{O}$ foco da pesquisa teórica embasou-se nos documentos oficiais orientadores para o ensino médio Parâmetros Curriculares Nacionais (PCN) e as Diretrizes Curriculares do Estado do Paraná (DCE), no conceito de Interdisciplinaridade e na busca da compreensão do conceito de energia nas Ciências da Natureza $(\mathrm{CN})$.

O ensino de Ciências nesta proposta não busca uma mera transmissão de conceitos, mas sim uma formação mais holística do sujeito: "Exige-se agora que o ensino consiga conjugar 
harmoniosamente a dimensão conceitual da aprendizagem disciplinar com a dimensão formativa e cultural" (CARVALHO, 2006 p. 3).

O conteúdo não pode estar desvinculado das questões e discussões presentes na sociedade, pois mesmo a formação dos conceitos científicos sofre influência da mesma. Atualmente, “[...] não se pode conceber o ensino de Ciências sem que esteja vinculado às discussões sobre os aspectos tecnológicos e sociais que essa ciência traz na modificação de nossas sociedades" (CARVALHO, 2006, p. 3).

O estudante do Ensino Médio (EM) possui uma grande quantidade de disciplinas diferentes que dialogam muito pouco entre si, mesmo quando tratam de conteúdos semelhantes. Neste contexto, o ensino de $\mathrm{CN}$ é visto a partir de enfoques diferentes, por meio das disciplinas de Física, Química e Biologia. Uma das propostas para tornar o ensino de CN mais interessante seria um ensino em que alguns temas semelhantes pudessem ser abordados de forma mais integrada. Daí a inspiração deste trabalho de pesquisa, que foi desenvolvido no âmbito da disciplina de Biologia, mas com foco na busca de formas de integrar os conteúdos de CN.

Esta necessidade de mudança no atual modelo de Ensino de Ciências também está registrada nos Parâmetros Curriculares Nacionais (PCN). No documento, a crítica a um modelo de simples memorização é reforçada ao se afirmar que o Ensino de Ciências centrado na memorização dos conteúdos, fora de contexto social, cultural ou ambiental, resulta em uma aprendizagem momentânea, que não se sustenta a médio ou longo prazo (BRASIL, 2002).

Delizoicov e Angotti (2009), por sua vez, propõem que o Ensino de Ciências deve estar pautado, inicialmente, no conhecimento do dia a dia para, posteriormente, tornar-se uma construção do conhecimento científico para o educando.

Assim, durante a exposição do conteúdo Ecologia, foi proposta a construção de um modelo didático experimental de biodigestor. Nesta proposta metodológica, além de construir o biodigestor, os alunos fizeram observações sobre as transformações da matéria orgânica e produção de gás metano ocorridas durante o processo de biodigestão. Estes processos foram associados ao tema energia, o conceito comum às $\mathrm{CN}$ escolhido como ponte integradora deste trabalho.

A análise dos relatórios foi realizada como propõe Bardin (2006), com enfoque na análise de conteúdo

\section{Revisão de Literatura}

Quanto ao aprendizado disciplinar da Biologia, cujo cenário é a Biosfera, o PCN relata que o mesmo é inseparável das demais ciências. "O conhecimento de Biologia deve subsidiar o 
julgamento de questões polêmicas, que dizem respeito ao desenvolvimento, ao aproveitamento de recursos naturais e à utilização de tecnologias que implicam intensa intervenção humana no ambiente [...]" (BRASIL, 1998, p.10). Este mesmo documento menciona que:

Mais do que fornecer informações, é fundamental que o ensino de Biologia se volte ao desenvolvimento de competências que permitam ao aluno lidar com as informações, compreendê-las, elaborá-las, refutá-las, quando for o caso, enfim compreender o mundo e nele agir com autonomia, fazendo uso dos conhecimentos adquiridos da Biologia e da tecnologia (BRASIL, 1998, p.19).

Esta forma de visualizar o ensino da Biologia exige alterações no modo de praticar o currículo. $\mathrm{O}$ estudante precisa perceber as relações do conhecimento historicamente acumulado com seu cotidiano e as alterações que provoca em seu meio "...muitas vezes tendo que abandonar práticas e visões de mundo ultrapassadas e valorizar práticas e conceitos que integram as ciências; formular questões, diagnosticar e propor soluções para problemas reais..." (BRASIL.1998, p. 12).

A construção de competências dependente do desenvolvimento de conteúdos nas salas de aula. Os conteúdos, tratados de modo a integrar vários saberes, que possuem uma ligação intrínseca, podem se comunicar e produzir um conhecimento mais profundo. Para que isto ocorra, é necessário um diálogo entre os saberes que vêm sendo expostos de forma fragmentada na escola. Nessa perspectiva, a interdisciplinaridade propõe um contato entre os saberes de diversas disciplinas em favor de uma compreensão mais integrada.

$\mathrm{Na}$ proposta dos PCN não se quer desfazer das disciplinas. "É preciso reconhecer o caráter disciplinar do conhecimento e, ao mesmo tempo, orientar e organizar o aprendizado, de forma que cada disciplina, na especificidade de seu ensino, possa desenvolver competências gerais" (BRASIL, 2002, p.12). O mesmo documento afirma que a interdisciplinaridade como processo de ensino possui mais facilidades quando ocorre em áreas do conhecimento que são próximas "Aparentemente, seria bem mais fácil estabelecer uma articulação entre as disciplinas de uma mesma área do que entre as de áreas diferentes, pois há elementos de identidade e proximidade no interior de cada área" (BRASIL, 2002, p. 18).

Para que a interdisciplinaridade seja efetiva é necessário encontrar temas ou assuntos que estejam em consonância com as disciplinas a serem trabalhadas. "Em seguida, a partir desses pontos, é preciso estabelecer as pontes e o trânsito entre as disciplinas, que nem sempre interligarão todas elas da mesma forma [...]" (BRASIL 2002, p. 19).

As práticas em relação à educação pública, em vigor no Estado do Paraná, segundo as Diretrizes Curriculares Estaduais (2008a), compreendem que o estudante é um sujeito fruto de seu tempo histórico, das relações sociais em que está inserido e que sua atuação no mundo é 
intrínseca à educação formal que recebe. Assim, o conhecimento proposto em sala de aula deve contribuir para a formação holística do ser humano.

Nesta concepção de mundo e de currículo, o conhecimento produzido pela humanidade deverá ser estudado por meio das disciplinas escolares. Este parecer assume que a melhor forma de atingir a formação pretendida é pela via de um currículo disciplinar, pois, para muitos, a escola será a única forma de acesso ao mundo letrado, ao conhecimento científico, à reflexão filosófica e do contato com a arte (PARANÁ, 2008a). Neste modelo, os conteúdos das disciplinas devem ser tratados pelos educadores de modo contextualizado e estabelecendo relações interdisciplinares entre eles.

Segundo Andery (1988 apud PARANÁ, 2008a, p.50) "a construção científica da Biologia deve ser entendida como processo de produção do próprio desenvolvimento humano. "A busca por entender e explicar os fenômenos naturais levou à construção de hipóteses e propostas de explicações dos mesmos. As explicações elaboradas cientificamente, por sua vez, são influenciadas pela produção histórica da humanidade.

Os padrões do pensamento biológico identificados compõem os chamados conteúdos estruturantes para a disciplina de Biologia, a partir dos quais abordam-se os conteúdos básicos e específicos.

Conteúdos estruturantes são os saberes, conhecimentos de grande amplitude, que identificam e organizam os campos de estudo de uma disciplina escolar, considerados fundamentais para as abordagens pedagógicas dos conteúdos específicos e consequente compreensão de seu objeto de estudo e ensino. (PARANÁ, 2008a, p. 55).

A metodologia de ensino da Biologia, nessa concepção, envolve um conjunto de processos organizados e integrados, dentre os quais, destacam-se: as aulas experimentais e momentos de reflexão teórica com base na exposição dialogada.

As aulas, desta forma, não são apenas experimentais ou apenas teóricas, mas pensadas de modo a assegurar a relação interativa entre o professor e o aluno, ambos tendo espaço para expor suas explicações, refletir a respeito das implicações de seus pressupostos e revê-los à luz das evidências científicas. (PARANÁ, 2008a, p. 53, 54).

A disciplina de Biologia deve ser capaz de relacionar diversos conhecimentos próprios de seu estudo com outras áreas do conhecimento, priorizando a formação de conceitos científicos, incluindo a possibilidade da mudança nos mesmos. Os conteúdos estruturantes, por sua vez, devem ser interdependentes, não devem ser seriados, nem hierarquizados.

Os conteúdos estruturantes das Ciências da Natureza, segundo (PARANÁ, 2008a; PARANÁ, 2008b; PARANÁ, 2008c) de Biologia, Química e Física foram definidos em 
diretrizes próprias para cada disciplina e são mencionados no Tabela 1, face ao trabalho interdisciplinar que motiva o presente trabalho.

Tabela 1 - Conteúdos Estruturantes das Ciências Naturais segundo as DCES-PR (PARANÁ, 2008a; PARANÁ, 2008b; PARANÁ, 2008c)

\section{Biologia}

Organização dos Seres Vivos

Mecanismos Biológicos

Biodiversidade
Física

Movimento

Termodinâmica

Eletromagnetismo

\section{Química}

Matéria e sua natureza

Biogeoquímica

Química sintética

Manipulação Genética

Fonte: (PARANÁ, 2008a; PARANÁ, 2008b; PARANÁ, 2008c)

É interessante notar que todos estes conteúdos estruturantes apresentam, em maior ou menor grau, inter-relações com o conceito de energia. Na Biologia (PARANÁ, 2008a), a Organização dos Seres Vivos, por exemplo, pode ser compreendida em função da disponibilidade de energia nos ecossistemas. A Biodiversidade, por sua vez, relaciona-se diretamente com a energia disponível para a mantença e a reprodução. A biogeoquímica, conteúdo estruturante de Química (PARANÁ, 2008c), também corresponde a conteúdo específico da Biologia que se relaciona ao assunto energia. No caso da Termodinâmica, conteúdo estruturante da Física (PARANÁ, 2008b) também existem ligações com o conceito de energia e implicações nos sistemas biológicos. Assim, percebe-se a interação dos conteúdos das Ciências da Natureza e, além disso, abre-se a perspectiva de que os fenômenos naturais, para serem compreendidos de forma plena, necessitam um olhar que permeie as várias abordagens disciplinares, por meio da interdisciplinaridade. Neste contexto, o conceito de energia permite favorecer este olhar, tendo em vista diferentes enfoques.

No Ensino Médio, o termo energia é utilizado em inúmeras disciplinas, mas o rigor com a mesma, na maioria das vezes cabe à Física. Por exemplo, ao mencionar energia potencial, o aluno que a reconhece irá se referir a conceitos e utilização do termo na Física, sem reconhecer a mesma nos processos químicos e biológicos; o mesmo ocorre com a energia cinética.

Os alunos, em geral, não reconhecem que o conceito de energia que o professor ou professora de Química, Física e Biologia ensinou possui as mesmas características, que são conservação e transformação, independentemente da disciplina que a está abordando nas Ciências Naturais.

Existe, a rigor, a necessidade do aluno/a entender a conservação da energia, e que a mesma pode ser transferida ou convertida de uma forma para outra, mas nunca criada ou destruída. Isto é parte integrante no avanço da compreensão do conceito. 


\section{A Interdisciplinaridade}

Uma das funções da escola é habilitar o indivíduo para a vida em sociedade, por meio das disciplinas ministradas em sua grade curricular. As Ciências da Natureza, Biologia, Química e Física, são de importância vital para uma compressão do mundo que se transforma muito rápido do ponto de vista científico e tecnológico.

O saber dividido em disciplinas trata os conhecimentos de forma específica e em partes, com foco restrito naquela área de conhecimento. A aprendizagem, neste contexto, é linear, não permitindo reflexões amplas que articulam as temáticas da sala de aula e a realidade vivida pelos estudantes. Este modelo contribui para fomentar a alienação e a desmotivação dos alunos, que não se percebem, por exemplo, como parte dos fenômenos naturais. Portanto, eles não são estimulados a criticar as informações e/ou o conhecimento que chega a eles. Esta forma habitual de educação também sufoca a criatividade e a conexão entre as disciplinas. Esta crítica é corroborada por Freire (1987), que buscava uma educação voltada à transformação do sujeito, o qual deveria compreender a realidade de forma crítica. Para isto, a educação deveria estar ligada ao conhecimento crítico da totalidade e do contexto.

[...] faltando aos homens uma compreensão crítica da totalidade em que estão captando-a em pedaços nos quais não reconhecem a interação constituinte da mesma totalidade, não podem conhecê-la. E não o podem porque, para conhecêla, seria necessário partir do ponto inverso. Isto é, lhes seria indispensável ter antes a visão totalizada do contexto para, em seguida, separarem ou isolarem os elementos ou as parcialidades do contexto, através de cuja cisão voltaria com mais claridade à totalidade analisada (FREIRE, 1987, p. 55).

Portanto, numa perspectiva freiriana busca-se caminhos que nos permitam uma educação crítica, formadora e emancipadora.

Assim uma das formas segundo a qual procuramos entender a interdisciplinaridade surge das relações de interdependências e de conexões recíprocas entre as disciplinas. Isto sugere uma articulação, cooperação e intercâmbios de ações disciplinares que vislumbram interesses comuns para enriquecimentos mútuos, pois, "[...] a exigência interdisciplinar se manifesta desde as origens da ciência moderna, como a necessidade sentida de uma compreensão em face de fragmentação inexorável do horizonte do saber" (GUSDORF, 2006. p. 4). Portanto, ganha corpo a noção de que uma compreensão ampla dos fenômenos naturais necessita que se lance mão de uma abordagem pelo olhar de várias disciplinas do currículo.

Biologia, Química e Física apresentam aproximações e distanciamentos, pois seus domínios de estudo muitas vezes possuem pontos comuns, havendo conceitos e fenômenos que fazem a intersecção entre elas. "Por isso, o tipo de categorias a que pertencem os fenômenos 
observáveis dependentes do domínio de estudo determinará o nível categorial de integração teórica dos conceitos fundamentais e unificadores" (HECKBAUSEN, 2006, p. 81). Assim, os limites observados no interior de algumas disciplinas apontam para a necessidade de correlação, então, procurar noutras disciplinas próximas ideias ou métodos renovados, pode servir para o propósito desta unificação.

$\mathrm{Na}$ busca de superar o caráter puramente disciplinar do entendimento de um fenômeno natural Angotti (1991), propõe que existem quatro conceitos que são unificadores entre as disciplinas de ciências que são: Transformações (T), Regularidades (R), Energia (E) e Escalas (ES).

Com os conceitos unificadores, Angotti (1991) fundamenta a possibilidade de articular e organizar conhecimentos aparentemente distintos em níveis intra e interdisciplinares. Para o autor, conceitos unificadores vinham ao encontro de:

[...] aproximar as várias ciências, mantidos os níveis de cognição preservados. Principalmente, queremos estabelecer vínculos e estreitamentos entre cientistas, professores e currículos; para que se estabeleçam diálogos com estudantes e crianças. Mais ainda, que os 'conteúdos' sejam definidos por TEMAS significativos de amplo alcance e que os conceitos unificadores sejam sistematicamente utilizados para que as transferências ocorram, as desejadas apreensões ocorram, e daí o conhecimento em CN possa a vir a ser instrumento real de exercício para qualquer profissão, atividade da cidadania. Sobretudo, para que o nível de cultura elaborada seja mais partilhado (ANGOTTI, 1991, apud MENDES SOBRINHO, 1998, p. 163).

A identificação destes conceitos está norteada por parâmetros epistemológicos e pedagógicos. "Eles podem dirigir as totalidades, sem descaracterizar as necessárias fragmentações (ANGOTTI, 1993)". Os conceitos unificadores buscam assim a construção de elos entre as $\mathrm{CN}$ na procura de um conhecimento crítico das ciências.

A utilização de Energia como conceito unificador, conforme argumenta Angotti (1991), "poderá contribuir significativamente para a inserção cultural de C\&T em nossa sociedade". Pois como pensar a sociedade atual sem o conhecimento da transformação e conservação da energia, em uma sociedade tecnológica e na dependência da mesma. José André Peres Angotti (1991), ainda, ao falar do conceito, revela que o mesmo trará conhecimento não só destas questões, mas acerca do universo [...] "Melhor para os educandos, que terão chance de alcançar concepções sobre o universo em sua dinâmica" (ANGOTTI, 1991, p. 126-127).

A utilização dos conceitos unificadores se manifesta, portanto, na busca de um Ensino de Ciências com característica interdisciplinar que procura uma formação holística, emancipadora e crítica do aluno. É neste fundamento que se enquadra a presente dissertação, ao utilizar a 
construção de um Biodigestor como instrumento de integração dos fenômenos das CN durante o ensino de Ecologia.

O biodigestor é um produto tecnológico que foi introduzido no Brasil na década de 1970 por causa da crise de petróleo que se instalava no país. No interior, do Biodigestor acontece a fermentação anaeróbia da biomassa, ou decomposição da matéria orgânica que dá origem ao biogás. O biogás pode ser utilizado, entre outras formas: para aquecimento de fogões, como combustível para motores de combustão interna, para a geração de energia elétrica, entre outros. É evidente, portanto, nos processos envolvendo o biodigestor, a presença dos conceitos unificadores Transformações e Energia.

\section{Procedimentos Metodológicos}

O projeto foi desenvolvido na disciplina de Biologia sempre tentando aproximar o conceito de energia da Física e da Química

A proposta desenvolvida baseia-se na visão geral de que a energia é o que possibilita toda a vida na Terra.

O presente trabalho pode ser tido como uma pesquisa de natureza qualitativa participante, pois busca envolver os estudantes e o pesquisador, no desenvolvimento de metodologias para a superação de disciplinas que pouco dialogam entre si, construindo coletivamente os possíveis instrumentos para o processo ensino-aprendizagem dos conceitos das Ciências Naturais. Para Brandão (2006), a pesquisa participante é uma modalidade de conhecimento coletivo do mundo e das condições de vida das pessoas, grupos e classes populares.

Durante o trabalho, foi seguido o conteúdo curricular proposto pela Secretaria de Estado da Educação do Paraná (SEED-PR) e pelo projeto político pedagógico da escola em que o projeto foi desenvolvido. Houve aulas dialogadas nas quais os conteúdos foram abordados e, sempre que possível, dava-se ênfase a energia e suas transformações. O produto por se tratar de um Mestrado na modalidade Profissional é material complementar desta dissertação refere-se à construção de um modelo didático pedagógico experimental de biodigestor, o qual norteou o desenvolvimento da dinâmica de sala de aula.

A pesquisa foi realizada em uma escola estadual, no Município de Araucária, no Estado do Paraná. A mesma se encontra num bairro próximo da região central da cidade. A escola atende alunos oriundos de todas as regiões do município. É uma escola de médio porte, funcionando em três turnos. No local existem muitos problemas em relação à estrutura física. A escola funciona de forma precária, com duas sedes, uma na escola propriamente dita, e outra em um espaço alugado, em uma capela, a duas quadras da sede. Além disso, a escola enfrenta 
problemas como salas pequenas para o número de alunos, falta de laboratório de ciências e de informática, dificuldade de aquisição de materiais para pesquisas, dentre outros.

O público envolvido na pesquisa foram alunos do Ensino Médio regular, do turno noturno, em duas turmas de terceiros anos. As turmas possuíam 45 e 48 alunos, respectivamente, com idades variando de 16 a 23 anos. Muitos dos estudantes já estão inseridos no mundo de trabalho. O referido estudo foi realizado no período de fevereiro a junho de 2014 , o que compreende um semestre letivo.

O conteúdo escolhido foi Ecologia, no entanto, foi também desenvolvido durante quatro horas aulas o conteúdo de metodologia científica, incluindo discussões sobre o rigor necessário para técnicas experimentais, confecção de relatórios técnico-científicos e relatórios de observação.

Houve um contato inicial com os alunos para expor alguns modelos de biodigestores e solicitar a participação no projeto. Foi feita a proposta que os alunos se dividissem em grupos de até oito pessoas. A divisão ficou a critério dos estudantes, o que resultou e num total de quinze grupos nas duas salas. Por consequência, houve quinze biodigestores construídos. Mapas conceituais foram realizados, pelos estudantes, ao final do trabalho, após a observação do processo de biodigestão.

A construção do biodigestor (fotografia 1), ocorreu no ambiente de sala de aula. A matéria orgânica colocada foi composta de restos da cozinha, carnes e fezes de cavalo. Ela foi escolhida pelos alunos que fizeram a escolha tendo em vista a motivação de "gerar mais energia". Foi colocado um quilo de matéria orgânica para um litro e meio de água (de abastecimento). A matéria orgânica foi pesada em balanças de precisão e a água medida com béquer, buscando rigor na mensuração dos volumes.

\section{Fotografia 1 - Biodigestor concluído com sucesso.}

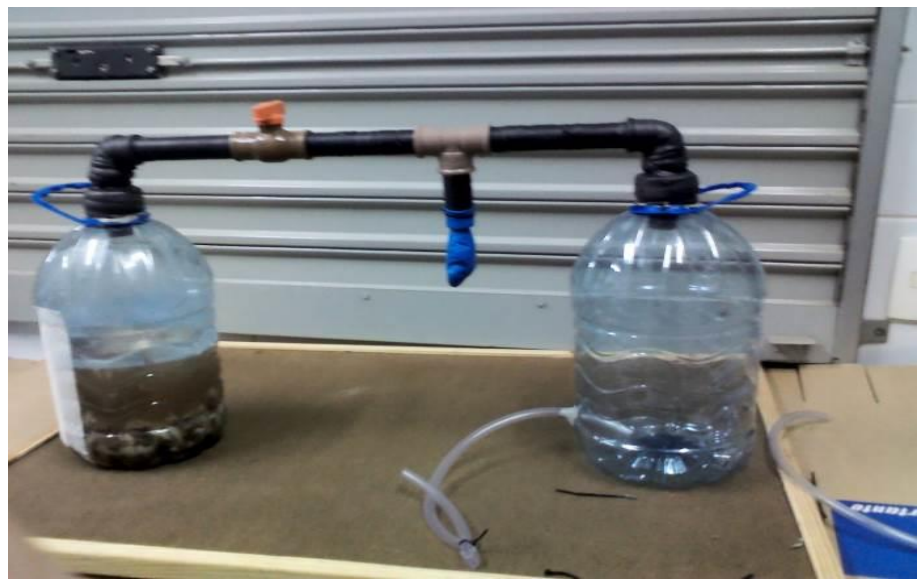

Fonte: Autoria estudantes terceiro ano Ensino Médio-2014. 
Durante todo o processo de biodigestão, foram feitas observações que estão registradas em fotos e relatórios. As observações dos processos de biodigestão deveriam ocorrer duas vezes por semana, no horário de aula. Os dados eram anotados em um "planejador de eventos", no qual eram relatados o dia de observação e as mudanças ocorridas, divididas em dois blocos: Biológicas e Físico/Químicas. Nas Mudanças Biológicas, deveriam ser observados: presença de fungos, cor e odor. Nas mudanças Físico/Químicas: aspecto do material, presença de gases (bolhas), temperatura ambiente e temperatura do sistema (biodigestor). Além disso, havia o relatório de observações aleatórias, no qual os estudantes deveriam descrever qualquer outro fato relevante observado.

As aulas dialogadas ocorreram durante todo o processo em que foi trabalhado o conteúdo Ecologia e a interação entre os conteúdos, que busca mostrar que a energia permeia os conteúdos estudados.

\section{Inter-relação da energia com os demais conteúdos da Ecologia.}

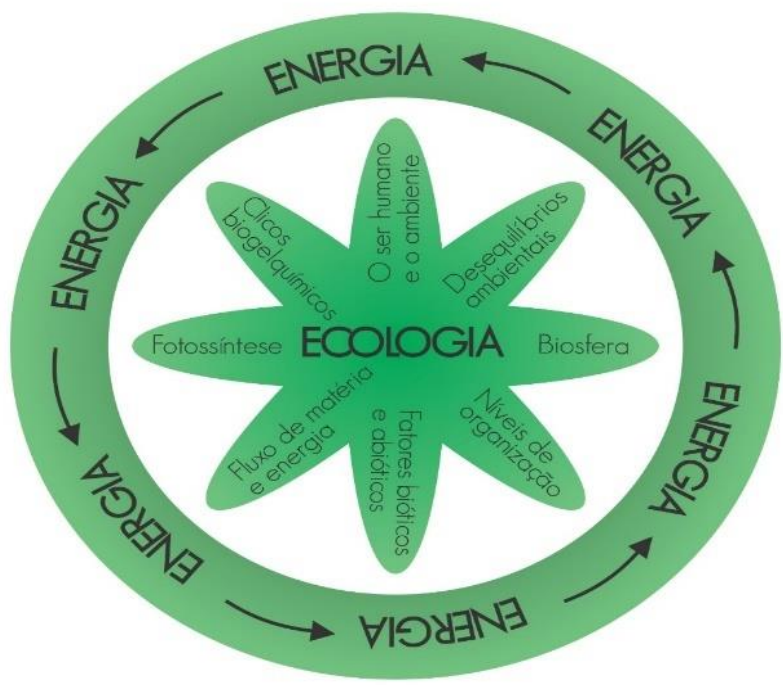

Fonte: Autora (2014).

Esta pesquisa se enquadra em uma pesquisa do tipo qualitativa participante. A perspectiva qualitativa de análise de conteúdos escolhida é um conjunto de técnicas de análise de comunicações que tem como objetivo ultrapassar as incertezas e enriquecer a leitura dos dados coletados (BARDIN, 1977).

Foi utilizada a metodologia proposta por Bardin (1977), que alerta que apelar para instrumentos de investigação laboriosa de documentos seria situar-se ao lado daqueles que 
pretendem dizer não "à ilusão da transparência", tentando afastar os perigos da compreensão espontânea BARDIN (1977).

Para a análise da pesquisa, deu-se ênfase a dois momentos: os mapas conceituais e os relatórios, aqui por se tratar de um recorte só apresentaremos os relatos obtidos nos relatórios.Para facilitar a análise utilizamos como chaves de enumeração das respostas analisadas o código $\mathbf{R}$, para os relatórios, seguido do número dado ao mesmo de forma aleatória de 1 a 13 . Foram elencadas 4 categorias de análise,Percepção da interdisciplinaridade entre as CN; Ensino Interdisciplinar, e conexões com o cotidiano; Energia, percepção da transformação e conservação; Energia e necessidade social da mesma aqui daremos enfoque as duas últimas.

\section{Resultados}

Energia, percepção da transformação e conservação, esta categoria busca visualizar se o aluno pode perceber durante todo o desenvolvimento do projeto que energia não se cria nem se perde apenas se transforma.

R1“Tão importante quanto à questão energética, é a questão de percepção da energia que o projeto nos trouxe. Através do biodigestor, é possível concluir o fato natural de que a energia não pode ser produzida, mas sim transformada.".

R1“Através da decomposição da matéria-energia é possível ser transformada uma nova forma de energia, uma forma gasosa. E esta é a verdadeira essência da energia presente no universo, uma energia que não pode ser criada, mas sim transformada.".

No recorte acima o princípio da conservação de energia, ou seja, um tipo de energia pode ser convertido à outra, ficou bem claro párea os alunos os mesmos enfatizam que durante o processo a energia não foi perdida e sim convertida em outra forma.

R2"Felizmente conseguimos atingir todos nossos objetivos, principalmente objetivos gerais, pois analisamos a transformação da energia, que em um primeiro momento estava na forma de energia a potencial química e ao ficar isolada de oxigênio começa a se decompor, transmitindo essa energia para as bactérias e fungos que são responsáveis pela decomposição da matéria orgânica.".

R2“Através da fotossíntese, a energia luminosa é transformada em energia potencial química. Após esse processo a planta, utiliza uma parte da energia química para a manutenção de seu metabolismo, e o que resta dessa energia é transmitida para outros seres tróficos de 
uma teia alimentar".

R2“Isso nos mostra que as substâncias que foram introduzidas no interior do biodigestor continham energia. Essa energia é transmita para as bactérias que se multiplicam com facilidade devido à ausência do oxigênio, e isso dá "forças" para elas decomporem a matéria orgânica, gerando assim diversos gases, que mais tarde poderão ser utilizados como energia térmica ou até mesmo energia elétrica.”.

Nestes trechos o princípio da conservação de energia é mostrado pelos alunos, existe a preocupação de nomear algumas manifestações da energia (potencial química, energia luminosa e energia térmica), em momentos diferentes do processo de biodigestão. $\mathrm{O}$ entendimento sobre as transformações da energia se tornou frequente e com relações amplas frente ao conteúdo abordado.

R3“Quando um organismo se alimenta do outro nas relações da cadeia alimentar, há transferência tanto de energia quanto de matéria. $O$ processo de transferência de energia começa pelo sol. A energia, Solar, captada e transformada pelos produtores, é devolvida ao meio na forma de energia térmica pelos próprios produtores, consumidores e decompositores. Trata-se de um fluxo unidirecional."

O recorte mostra uma grande interação dos conteúdos abordados nas aulas dialogadas com o conteúdo observado no biodigestor. Os estudantes conseguem abordar as relações tróficas com a captação de energia e suas transformações ao longo das cadeias alimentares.

Em todos os recortes fica claro que os alunos compreenderam durante o desenvolvimento do projeto as transformações da energia e suas manifestações

Energia e necessidade social da mesma, esta categoria tratou de analisar se o estudante após vivenciar cada uma das mudanças ocorridas com a matéria orgânica, juntamente com o conteúdo teórico, seria capaz de perceber necessidade da energia na sociedade e formas alternativas da sua produção.

R2 "Atualmente existe alguns programas que incentivam a produção de biogás como fontes de energia alternativa, tendo com o maior destaque a parceria entre o MMA (Ministério do Meio Ambiente), MME (Ministério de Minas e Energia) e o ANNEL (Agencia Nacional de Energia Elétrica), que se dedicando para o desenvolvimento desse projeto". R2 "Outra iniciativa que está sendo proposta é o Programa de compra de resultados futuros 
no Manejo de Resíduos Sólidos, cujo objetivo principal é a busca de sustentabilidade no processamento de resíduos. Um dos aspectos negativos do metano é que ele participa da formação do efeito estufa, colaborando, desta forma, para o aquecimento global. Da mesma maneira que tem os malefícios para o ambiente, a produção do biogás tem muitas vantagens, que podem ser soluções para problemas ambientais no futuro".

R2 “Além disso, o biogás é, com certeza, uma importante fonte energética substituta para os combustíveis derivados do petróleo, como a gasolina e o diesel. E, sobretudo, o uso do biogás representa uma alternativa real ao uso do GLP, ou gás de cozinha, ainda amplamente utilizado por todos nós.”.

Este Recorte o grupo mostra uma preocupação em buscar informações sobre programas promovidos pelo governo para solucionar os problemas em relação a energias alternativas como o biogás. Os estudantes mostram-se preocupados com fatores que em outra abordagem seria difícil visualizar. Assim fica evidente a procura de informações relativas a processos que sejam sustentáveis em relação a obtenção de combustíveis e energia. Revelando ocorreu uma sensibilização da necessidade de obtenção dos mesmos, contudo de forma limpa e responsável.

R4 "O presente estudo teve como objetivo o desenvolvimento de um sistema de biodigestão com a finalidade de produzir biogás com potencial de ser utilizado como fonte de energia alternativa.".

Ao estipular seus objetivos os alunos já idealizavam aprender sobre processos alternativos de obtenção de energia. A observação da biodigestão corroborou no sentido de sensibilizá-los a respeito da necessidade da energia na sociedade atual.

R9 "Porém o essencial foi o aprendizado, que o biodigestor não está no estado defasado e sim presente na vida de muitas pessoas que habitam as regiões rurais, e que fazem do biodigestor uma grande fonte de energia para suas casas. Além disso, o biodigestor é muito benéfico para o meio ambiente, pois é uma excelente alternativa tecnológica para tratamento dos dejetos.”.

A preocupação com regiões rurais aparece neste recorte e mostra o nível desenvolvimento de interações, feitas pelos alunos, em relação a vários temas entre eles a necessidade de obtenção de energia. 
Em todos os recortes ficou claro que os alunos tiveram a percepção que existem formas alternativas de captação de energia, entre elas o biogás e sua posterior transformação em energia. Como mostrado não se atingiu a totalidade dos relatórios contemplando todas as categorias elencadas. Os resultados sugerem que, os alunos avançaram em seus conhecimentos sobre energia. A interpretação e explicação das situações apresentadas tiveram boa qualidade. $\mathrm{O}$ conceito de energia como fio condutor foi positivo, pois trouxe os conteúdos mais próximos da realidade dos mesmos e ainda serviu com nó de significações entre os conceitos.

\section{Considerações Finais}

A confecção do biodigestor e sua observação, foram fatores determinantes na compreensão do ciclo da matéria orgânica e suas interações com algumas formas de obtenção da energia na sociedade. A energia e o seu uso na sociedade atual, na possível melhoria da qualidade devida dos sujeitos. Como um ponto a ser pensado, é preciso reconhecer que o conhecimento sobre a biodigestão, foi uma ferramenta que contribuiu efetivamente para a ampliação da capacidade de compreensão da produção de energia.

As práticas em torno da observação do biodigestor possibilitaram uma aproximação das ciências naturais e esta aproximação a reflexões em torno do fio condutor proposto que é a energia. Este estudo também apontou para possibilidade de uso dos conceitos unificadores, energia e transformações, como possibilidade de integração de conteúdos vistos de forma isolada. Utilizar estratégias diferenciadas para a exposição de conteúdo das $\mathrm{CN}$ pode servir como forma de motivação para aprendizagem de conteúdos destas ciências.

Nesta proposta, a busca pela superação de aulas mecanicistas e excessivamente tradicionais enfrentou vários obstáculos como: falta de laboratório; falta de verbas para compra de materiais; poucas aulas para desenvolver o conteúdo e as atividades experimentais e de observação, sem ao menos ter iluminação adequada no local de implementação da atividade.

Por meio da construção e observação do biodigestor se permitiu ao estudante cultivar: sua criatividade, seu imaginário, sua vontade de estar na sala de aula trabalhando em grupos, seus questionamentos. Em consonância a isto, a aprendizagem de um conjunto de conceitos científicos, que o mesmo poderá lançar mão ao longo de sua vida, mesmo fora do contexto escolar. Além disso, pode-se verificar que a utilização de uma metodologia de ensino diferenciada, na qual os estudantes são estimulados a serem sujeitos de sua aprendizagem com questionamentos e comentários, proporcionou em sala de aula um clima de construção de conhecimento. Por muitas vezes os questionamentos não eram respondidos na hora, e na aula seguinte os próprios alunos já haviam buscado respostas. Assim se alcançou entre essas aulas e a 
proposta que "ensinar não é transferir conhecimentos, mas criar as possibilidades para a sua produção ou a sua construção" (FREIRE, 1996, p. 22).

Quanto ao ambiente escolar como um todo se verificou dificuldades de aceitação da proposta, mas a mudança não se faz de modo imediato, precisamos acreditar que aos poucos faremos uma escola com alternativas para o desenvolvimento dos estudantes tendo como fator primordial a formação de um sujeito com consciência plena do seu papel social.

\section{Referências}

ANGOTTI, José André Peres. Conceitos unificadores e ensino de física. Revista Brasileira de Ensino de Física V. 15, n. ${ }^{\circ}$ a 4, p. 191 - 198, 1993.

Fragmentos e totalidades no conhecimento científico e no ensino de ciências. Tese de doutorado. Universidade de São Paulo, São Paulo, 1991.

BARDIN, Laurence. Análise de conteúdo(L. de A. Rego \& A. Pinheiro, Trads.). Lisboa: Edições 70, (2006). (Obra original publicada em 1977)

Análise de conteúdo. Tradução de Luís Antero Reto e Augusto Pinheiro. Lisboa: Edições, v. 70, 1977.

BRANDÃO, Carlos Rodrigues. A pesquisa participante e a participação da pesquisa: um olhar entre tempos e espaços a partir da América Latina. Pesquisa participante: a partilha do saber. Aparecida: Ideias e Letras, p. 21-54, 2006.

BRASIL. Constituição Federativa da República. Brasília, 1988.

- Ministério da Educação - MEC, Secretaria de Educação Básica. Orientações Curriculares para o Ensino Médio: Ciências da natureza, matemática e suas tecnologias. Brasília, 2002.

CARVAlHO, Ana Maria Pessoa. Ensino de Ciências: unindo pesquisa à prática/ Anna Maria Pessoa de Carvalho, (org.). São Paulo: Pioneira Thomson Learning, 2006.

DELIZOICOV, D.; ANGOTTI, J. A.; PERNAMBUCO, M. M. Ensino de ciências: fundamentos e métodos. 3 ed. São Paulo: Cortez, 2009.

FREIRE, Paulo. Medo e ousadia: o cotidiano dos professores. Rio de Janeiro: Paz e Terra, 1987.

Pedagogia da Autonomia. São Paulo: Paz e Terra, 1996.

GUSDORF, Georges. et al. Interdisciplinaridade: antologia. Porto: Campo das Letras, 2006.

HECKHAUSEN, Heinz. et al. Interdisciplinaridade: antologia. Porto: Campo das Letras, 2006.

MENDES SOBRINHO, José Augusto de Carvalho. Ensino de Ciências e Formação de Professores: Na escola normal e no curso de Magistério, 307f. Universidade Federal de Santa Catarina. Tese Doutorado, (Centro de Ciências da Educação) .1998.

PARANÁ, Diretrizes Curriculares da Disciplina de Biologia Paraná. Curitiba, 2008a.

Diretrizes Curriculares da Disciplina de Física Paraná. Curitiba, 2008 b.

.Diretrizes Curriculares da Disciplina de Química Paraná. Curitiba, 2008c.

SILVA, Z. R. O ensino de Ecologia mediado pelo conceito unificador energia: $O$ biodigestor enquanto modelo didático para uma abordagem interdisciplinar 2015. Dissertação Mestrado 
FAZ CIÊNCIA, VOL. 20, N. 31, JAN/JUN DE 2018 - P. 109-125

160 f. Universidade Tecnológica Federal do Paraná. Curitiba 2015. Disponível em: http://repositorio.utfpr.edu.br/jspui/handle/1/1347 